\title{
Putting Scaffolding Into Action: Preschool Teachers' Actions Using Interactive Whiteboard
}

\author{
Bourbour Maryam ${ }^{1,2}$ (D) Högberg Sören ${ }^{2} \cdot$ Lindqvist Gunilla $^{2,3}$
}

Published online: 7 September 2019

(c) The Author(s) 2019

\begin{abstract}
This study aimed to explore preschool teachers' actions in order to support children's learning processes in a context where an interactive whiteboard (IWB) is used. Five preschool teachers and 22 children aged 4-6 were video observed in 2017 and early spring 2018 over a period of 5 months. The findings of the study revealed 21 scaffolding actions which preschool teachers used including: Concretizing, Questioning, Instructing, Providing space, Affirming, Providing feedback, Inviting, Watching, Laughing together, Approaching, Standing/sitting beside, Simplifying, Filling in the blanks, Confirming, Participating, Challenging perception, Challenging thought, Explaining facts, Displaying, Explaining solutions, and Referring back. By characterizing teachers' actions in relation to different scaffolding functions, the relationship between action and scaffolding function was particularly clarified. Six of the functions, including recruitment, direction maintenance, marking critical features, reduction in degrees of freedom, frustration control and demonstration were aligned with Wood et al.'s (Child Psychol Psychiatry 17:88-100, 1976) theoretical framework. By identifying two additional functions, i.e., mutual enjoyment and participation in the activity, more importantly the study contributed to the development of Wood et al.'s (Child Psychol Psychiatry 17:88-100, 1976) theoretical framework. It can be said that the findings of the study expanded and deepened our understanding regarding scaffolding processes and the ways they can be implemented in teaching practices.
\end{abstract}

Keywords Scaffolding $\cdot$ Preschool teachers' actions · Interactive whiteboard · Scaffolding functions

\section{Introduction}

In our time, maybe more than ever, there are great expectations for how education can strengthen the development of society. In this process, hopes have been articulated for new digital technology to support young children's learning. Great investments have been made to make use of the assumed benefits. Yet the most influential factor that has repeatedly been highlighted is the teacher both in general as well as in particular, when it comes to how different devices

Bourbour Maryam
mabo@du.se
Högberg Sören
sho@du.se
Lindqvist Gunilla
gln@du.se
Örebro University, Örebro, Sweden
University of Dalarna, Falun, Sweden
University of Uppsala, Uppsala, Sweden

are used (Plowman and Stephen 2007, 2013; Nikolopoulou 2014). The introduction of digital technologies per se cannot necessarily transform the process of teaching and learning (McGarr 2009).

In this article, the focus is placed on preschool teachers' actions in a Swedish context as they teach in educational settings when an interactive whiteboard (IWB) is used. The Swedish curriculum for preschool (The Swedish National Agency for Education 2018a, b) highlights the importance of using digital technologies in a way that stimulates children's learning and development. The curriculum also points out that preschool teachers are expected to create a rich learning environment to enable and support children's development. How preschool teachers teach is an underdeveloped area of knowledge, partly explained by the fact that Swedish preschools traditionally have been based on a model that internationally can be labelled educare-not teaching in isolation - where education and care cannot be separated from each other (Bourbour et al. 2014). The point of departure for educational activities are said to be based on children's interest and initiatives (The Swedish National Agency for 
Education 2018a, b). In such an approach, childhood has value in itself, and is not merely regarded as a time of preparation for adulthood (Pramling Samuelsson and Asplund Carlsson 2008).

Furthermore, prior research indicates that early interventions in preschool can be more significant for adult life than later efforts, especially for disadvantaged children (Ruhm and Waldfogel 2012; The Swedish Research Council 2015). Hence, how teachers act in such educational environments is important to study (Lindqvist and Vinterek 2015).

This study, accordingly, addresses the above-mentioned knowledge gap, that is, preschool teachers' actions related to the requirements and conditions they have to adhere to in order to fulfil their mission. The intention is to highlight actions within different scaffolding functions (Wood et al. 1976) as different ways of teaching and by doing so, bringing an understanding of preschool teaching practice. Thus, the aim of the study is to explore preschool teachers' actions in order to support children's learning processes. As the study takes place in a context where interactive whiteboard (IWB) is used, the study may further contribute to a discussion of different opportunities made possible by the use of digital technologies.

\section{Swedish Preschools}

This study takes place in a Swedish preschool context, characterized by the following features: (a) Swedish early education was rated as of top quality (UNICEF 2008), (b) almost all children (84\%) between 1 and 5 years of age attend preschool, (c) Swedish preschools are governed by a curriculum where guidelines are specifically formulated (The Swedish National Agency for Education 2018a, b), (d) around 40\% of the staff are preschool teachers with a three and a half year university degree in early childhood education (The Swedish National Agency for Education 2018a, b), and (e) for many years, Swedish preschool has been known for its educare, an overall view on care, development and learning. However, in recent years, researchers have begun discussing a paradigm shift where the emphasis on learning has become more prominent in preschools' steering documents (Jönsson et al. 2012; The Swedish National Agency for Education 2015).

By emphasizing the pedagogical and school-preparing activities, the Swedish curriculum (2018) indicates that preschools should be characterized by an integrated approach that involves children's interests. This shift to child-centered education most likely influences preschool teachers' actions as well as what competences they need to develop in their teaching in order to conduct relevant activities (Sheridan et al. 2011). Preschool teachers, however, as Björklund $(2012$, p. 1) argues, usually do not show "sufficient awareness of their role and the importance of their own approach" to children's learning.
To summarize, since a noticed shift in the curriculum indicates a direction more towards learning processes and while most Swedish children aged 1-5 are educated by preschool teachers with a university degree in early childhood education, actions performed by Swedish preschool teachers are particularly interesting for further study (Jönsson et al. 2012; Lindqvist and Vinterek 2015).

\section{Teachers' Actions in Early Education}

Preschool teachers' key role in using digital technologies in preschool educational practices has been emphasized in earlier studies (Stephen 2010; Plowman and Stephen 2013; Nikolopoulou 2014; Masoumi 2015). The studies, have particularly, addressed the importance of teachers' beliefs and competences in using digital technologies in early education. However, in what way preschool teachers' key role is expressed in action has not been extensively researched.

Plowman and Stephen (2003) argue in their review study that digital technologies can either transform preschool teachers' actions or be made part of preschools' existing traditions. They also state that in order to transform the teachers' actions, the learning and teaching potentials of digital technologies need to be realized (Plowman and Stephen 2005). They furthermore suggest that pedagogical actions can be driven by teachers who understand children's ways of learning, rather than by technologies. Likewise Siraj-Blatchford (1999) argues that teachers' actions can only facilitate children's learning activities.

Stephen (2010) underlines the importance of the teachers' ways of scaffolding to support children's learning. Similarly, van de Pol et al. (2010), exemplify the teachers' use of modeling, questioning, and prompting exploration to scaffold children's learning. These ways aimed to scaffold children's "progress to new levels of knowing and acquisition" (Stephen 2010, p. 22). The use of such actions, however, may not assure the occurrence of scaffolding (van de Pol et al. 2010). Thus, this study intends to contribute to further our understanding of how and what kind of actions related to scaffolding processes can move children to new understandings using a particular digital technology such as IWB.

\section{IWB in Teaching}

By providing a variety of multi-dimensional resources and opportunities, IWB is often seen as a teaching artifact. In their study, Mercer et al. (2010) investigate how using IWB supports teachers in developing an appropriate 'dialogic space' for children to pursue collaborative educational activities. They found that teachers' use of IWB promotes children's discussions. They particularly highlighted that teachers, through developing and arranging learning material, in a specific sequence on the IWB scaffold children's 
collaborative engagement. Warwick and Mercer (2011) in another study examine the ways teachers' mediated presence may scaffold children's learning when using IWB. They conclude that the cultural environment can inform the ways teachers scaffold children's learning process when technologies are used. Warwick and Mercer (2011, p. 21) underline that the use of digital technologies such as IWB in educational situations should be structured in ways that "enable children's autonomous activity for extended periods".

De Vita et al. (2014) found that teachers' use of IWBs promote the students' lesson experiences in mathematics teaching. Teachers' actions in orchestration of learning environments on IWB can lead to construction of an effective learning and teaching environment and support students' learning. The researchers argue that the teachers' use of IWBs allow students to visualize multiple representations, compare, and map the relationship between different variables. In another study, De Vita et al. (2018) investigate the IWBs' potential in improving students' conceptual understanding, and fostering interactivity in secondary mathematics classrooms. Their findings show that teachers use two patterns-a problem-solving pattern and (b) an organizer pattern-in order to design and teach educational activities using IWBs. Furthermore, they put forward that the use of IWB has significantly contributed to students' discussions and collective construction of mathematical understandings.

\section{Theoretical Framing}

The theoretical perspective of this study is grounded in a socio-cultural perspective. Scaffolding is seen here as a way to employ the Vygotsky's zone of proximal development (ZPD) which provides individualized support based on the children's level of knowledge or ability to act in a certain context (Wells 1999). In Vygotsky's (1978) terms, the ZPD refers to the difference between what a child can do on his or her own and what he or she can do with support from an adult or a more competent peer. Hence, scaffolding is understood as customized support based on the children's ZPD, which accordingly refers to the supportive role of the teacher to extend children's learning (Edman Stålbrandt and Hössjer 2007). The way teachers are to act based on this perspective is expected to result in actions that will assist children within their ZPD, and support them to perform successfully (SirajBlatchford 2009).

Bruner (1978) developed the concept of scaffolding into a practical setting in terms of a "vicarious form of consciousness and control". Scaffolding, according to Bruner (1978, p. 19) "refers to the steps taken to reduce the degree of freedom in carrying out some task so that the child can concentrate on the difficult skill she is in the process of acquiring".
Consequently, scaffolding can be seen as a key feature in designing and conducting teaching activities which can cover a variety of actions by the teacher. In his study, Bruner (1983) showed that if children can be assisted by an adult, they can fulfill a task or solve a problem beyond the level at which they could naturally function. Thereby, he confirmed Vygotsky's ZPD. Opportunities for widening teachers' actions might also arise due to circumstances emerging from the fact that digital devices are brought into preschool settings, providing various kinds of learning environments as artifacts, which according to the sociocultural perspective will change the mediating process. Due to altered learning environments, children also might be able to succeed in a task that they would previously not have been able to do alone (Mercer and Littleton 2007; Copple and Bredekamp 2009).

Scaffolding as an instructional teaching method can be applied with just about any task (van de Pol et al. 2010). Preschool teachers' actions are also linked to the possibility of removing the scaffolding function, when children start to master a given task, since the scaffolding is no longer needed when they can accomplish the task on their own.

Teachers' actions are, as indicated above, linked to what has been described as functions of scaffolding processes. Wood et al. (1976) have discerned six different functions, which in our study serve as different classifications for giving teachers' actions different meanings. These six different functions of scaffolding processes are described as follows.

- Recruitment addresses teachers' actions in order to enlist children's interest to actively engage in an activity.

- Reduction in degrees of freedom addresses teachers' actions in order to simplify the task by reducing the number of constituent acts or reducing the size of the activities required to reach solutions. The teacher might fill in the blanks or let the learner perfect the component sub-routines that he or she can manage.

- Direction maintenance addresses teachers' actions in order to guide and keep the children in the pursuit of a particular objective.

- Marking critical features addresses teachers' actions in order to mark or highlight certain features of the task to help children solve the problem and identify correct responses.

- Demonstration addresses teachers' actions in order to demonstrate and model solutions so the child can imitate them.

- Frustration control addresses teachers' actions, such as face saving, in order to reduce a stressful activity to become less dangerous. 
In summary, the theoretical frame set by the socio-cultural perspective place a focus on teachers' actions in relation to different functions of scaffolding processes.

\section{Data-Collection and Analysis}

This empirical study was conducted through observations in a preschool in Sweden. The observations of the teaching activities were documented through video recordings. The fieldwork took place in a preschool with five preschool teachers and 22 children aged 4-6 during 5 months in 2017 and early spring 2018.

To find suitable preschools, contacts were made with the regional Centers for educational development across Sweden as well as virtual forums dedicated to enhance teachers' competences using IWB (e.g., Smartboardklubben in Swedish). Based on the information gained, contacts were established with a number of preschools in different cities in Sweden. Some of the preschools declined to participate for a variety of reasons including the re-organization of departments and educational activities. Finally, three preschools were eager to participate in the study. However, two of them were not suitable for the study since the preschool teachers did not use IWB actively in their pedagogical practices. Thus, the study was conducted with five preschool teachers in a preschool located in the center of Sweden. In order to meet the requirements of the study, the preschool teachers' ongoing and regular teaching when working with mathematical concepts using the IWB were observed in 18 teaching situations for a total of $306 \mathrm{~min}$. The teaching situations were chosen, partly since the curriculum explicitly states that preschools should develop children's ability to use mathematics to distinguish, express, examine and use mathematical concepts and relationships between concepts (The Swedish National Agency for Education 2018a, b).

The researcher who conducted the observations did not interfere in the planning of the activities nor in the ways the teachers designed and conducted their teaching using IWB. It was particularly emphasized that all of the participating teachers were free to plan and decide the time frame, the content, and their working methods.

To gather the empirical material, a camera was placed at the corner of the classroom behind the children to capture what happened on and around the IWB. All activities during the teaching situations were recorded and both the teachers and the children working with the IWB were in focus.

The empirical material was transcribed in detail, which resulted in 274 pages of text. The transcribed material was read and reread by the authors, as well as rechecked by returning to the recorded material in order to explore and discern what parts of the text could be considered as scaffolding processes. As a first step out of four (see Table 1) in the analysis process, a number of 772 meaning units, i.e., units of analysis in terms of short sentences, were selected. These meaning units were chosen on the basis of Wood et al.'s (1976) six scaffolding functions. Such a single meaning unit consists of either an excerpt referring to what the teacher says or what the teacher does in relation to the ongoing activity next to the IWB. Further, the combination of talk and a particular physical action performed by the teacher was taken into account when meaning units were constructed. These meaning units were further elaborated and evaluated in step 2-4.

The second step in the process of analysis was to describe the activity in relation to the chosen meaning unit. In the third step, the central verb that was used in the previous step of descriptive analysis was extracted and regarded as a

Table 1 The data analysis process step by step—eight examples

\begin{tabular}{|c|c|c|c|}
\hline Choice of meaning unit & Description of activity & Teacher's actions & Scaffolding function \\
\hline Teacher: Erik, can you come and try it & Teacher invites the child to participate & Inviting & Recruitment \\
\hline Teacher: Does circles have sides? & $\begin{array}{l}\text { Teacher gives the children a challeng- } \\
\text { ing question }\end{array}$ & Challenging thought & Direction maintenance \\
\hline Teacher puts the finger on the apple & $\begin{array}{l}\text { Teacher simplifies a previously given } \\
\text { task }\end{array}$ & Simplifying & Reduction in degrees of freedom \\
\hline $\begin{array}{l}\text { Teacher: this one costs two Crowns and } \\
\text { the others cost one Crown each }\end{array}$ & Teacher explains the task given & Explaining & Marking critical features \\
\hline $\begin{array}{l}\text { Teacher is walking up, standing right } \\
\text { next to the board and looking at the } \\
\text { board }\end{array}$ & $\begin{array}{l}\text { Teacher walks up and stands next to } \\
\text { the board }\end{array}$ & Approaching & Frustration control \\
\hline $\begin{array}{l}\text { Teacher shows practically how to spin } \\
\text { a piece of puzzle }\end{array}$ & $\begin{array}{l}\text { Teacher displays a solution with the } \\
\text { physical act }\end{array}$ & Displaying & Demonstration \\
\hline Teacher laughs/smiles & Teacher laughs with the children & Laughing together & Mutual enjoyment (NEW FUNCTION) \\
\hline $\begin{array}{l}\text { Teacher counts and stacks simultane- } \\
\text { ously }\end{array}$ & $\begin{array}{l}\text { Teacher joins in and participates in the } \\
\text { activity with the children }\end{array}$ & Participating & $\begin{array}{l}\text { Participation in the activity } \\
\text { (NEW FUNCTION) }\end{array}$ \\
\hline
\end{tabular}


summary of the teachers' actions. In some cases, the verb was combined with a clarifying noun or preposition. All the verbs identified were then considered as different categories which, as a final fourth step in the analysis, were evaluated in relation to Wood et al.'s (1976) six different scaffolding functions. The analysis resulted in 21 different categories of teachers' actions due to the researchers' conclusion that some similar verbs formed a shared category. As a result of the process, two further scaffolding functions were identified since a handful of teachers' actions could not fit into Wood et al.'s (1976) scaffolding functions.

\section{Ethical Considerations}

Ethical considerations were taken into account in accordance with Swedish ethical regulations for research (The Swedish Research Council 2017). The participants in the study were accordingly informed about their participation in the study, and the terms and conditions for their contribution. Information about the aim, method, and procedure of the study was given to the participants, including the preschool leader, teachers and children's guardians. The participating preschool teachers received a separate consent letter. Since the children were young and there was a risk that they would not fully understand the meaning of their participation in the current study, the children's guardians' written consent was required. Furthermore, the preschool children's consent to participate in the study and to be video-recorded was gained. To make children familiar with the researcher, the researcher visited the preschool on a couple of occasions and participated in various activities with the children in their daily practices. The researcher paid particular attention to children who appeared to be unwilling to participate in an observed situation. In such instances, the camera was positioned in a way that those children were not filmed.

In accordance with confidentiality and to protect the participants' identity, the preschool's name, teachers' names, the names of the children, and the names of their neighborhoods have been changed in the text. Each of the five participating teachers were observed on various occasions and each of the 18 teaching situations were named alphabetically and numerically as follows: A:1-A:6; B:1-B:3; C:1-C:4, D:1-D:3 and E:1-E:2. Each letter corresponds to the teacher and the following number corresponds to the exact teaching situation. The participants' images, presented below, were blurred and anonymized. Furthermore, the collected data have been used only for academic purposes, and have not been viewed by any unauthorized person.

\section{Results}

Analysis of the collected empirical data reveals preschool teachers' ways of scaffolding using IWB. The 21 categories of teachers' action are summarized in relation to scaffolding functions in Table 2.

Table 2 Teachers' actions in relation to scaffolding functions- the table is organized firstly on the basis of frequency between each Scaffolding function, secondly on the basis on frequency of Teachers' action within each Scaffolding function

\begin{tabular}{lll}
\hline Scaffolding function (Wood et al. 1976) & Teacher's action (772) & New identified scaffolding function \\
\hline Direction maintenance (231) & Challenging thought (89) & Concretizing (58) \\
& Questioning (51) & Instructing (33) \\
& Providing space (52) & Affirming (37) \\
Recruitment (221) & Providing feedback (100) \\
& Inviting (32) \\
& Watching (61) \\
& Laughing together (3) \\
Frustration control (101) & Approaching (77) \\
& Standing/sitting beside (24) \\
Reduction in degrees of freedom (77) & Simplifying (61) \\
& Filling in the blanks (9) \\
& Confirming (7) \\
Marking critical features (26) & Participating (36) \\
Demonstration (16) & Challenging perception (18) \\
& Explaining facts (8) \\
& Displaying (7) \\
& Explaining solution (7) \\
& Referring (2) \\
&
\end{tabular}


As indicated in Table 2, teachers used similar actions in relation to different scaffolding functions. For instance, in a number of observed situations, teachers challenged in order to keep children pursuing a particular task, and in other instances teachers challenged to highlight certain features of the task. In this sense, a similar action appears as different due to the related scaffolding function. In the following, the presentation of the results is based on the scaffolding functions.

\section{Direction Maintenance}

This scaffolding function addresses the ways teachers challenge children's thought, concretize the task, create guided questioning, and instruct children in their task.

Teachers' actions can be seen as a way of challenging the children in a large amount of data. In the observed data teachers challenge children's thoughts in order to keep them on task. For instance, in a teaching activity about parts and wholes, the teacher seems to challenge children's thought by asking questions like, "Could you explain why we call a triangles three-sided?".

An action categorized as concretizing appears when teachers use plastic cubes (i.e., Lego blocks) with geometrical shapes on the floor in front of the IWB to keep children on the task. By comparing the geometrical shapes on the floor and the IWB, the teacher brings in another way that children's learning can be scaffolded.

Further, guided questioning in activities is another action which is commonly seen in the observed situations. In the observed teaching situations, questioning may act as a catalyst for further discussion to create opportunities for children to analyze the mathematical phenomena.

The excerpt below illustrates an activity about parts and wholes. The activity begins with an introduction of big mandalas (geometric patterns such as circles, squares, and triangles) on the IWB. The children are asked to identify which shapes the mandalas consist of and then they choose a shape and paint it.

\section{Excerpt from Teaching Activity C: 3: Part and Whole I}

Teacher: My dear, what shapes can you see on the IWB? ((Points to the mandalas on the IWB and looks at Maria)) Maria: A circle

Teacher: Yes

Maria: A straight line

Teacher:((nods and looks at Maria)) [after (.) Straight lines ((looks at the board)) [after (.) Now there are many who have said straight lines. What are these straight lines?

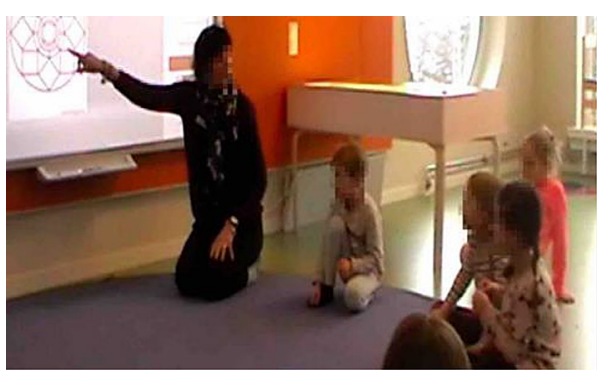

This excerpt illustrates how the teacher questions the concept of straight lines saying that "Now there are many who have said straight lines. What are these straight lines?" The questioning of the concepts as exemplified above can stimulate the children to think and analyze.

Further, in the collected data, instances where the teachers kept children on task by instructing them during their activities on IWB were observed. The instructions as guidelines can be undertaken in series of steps in different ways, including pointing and showing. In the following excerpt, the teacher uses the IWB to instruct the children to count and calculate money.

\section{Excerpt from Teaching Activity A: 4: Numerical Values of Money}

((Children play shop on IWB. Emil takes and puts the goods that he wishes to buy on the table next to the cashier. In order to pay for these items, he drags some coins and puts them toward the bottom of the board))

Teacher: ((comes closer to the IWB and points at the money)) [(.) You can put the coins (money) here next to the cashier so we can see them.

Emil: ((drags 4 Swedish Crowns next to cashier, and looks at the goods he has already put on the counter)) Teacher: ((stands up)) [(.) First you must count your money and make sure you have enough. ((points to the coins that Emil has put next to cashier)) 


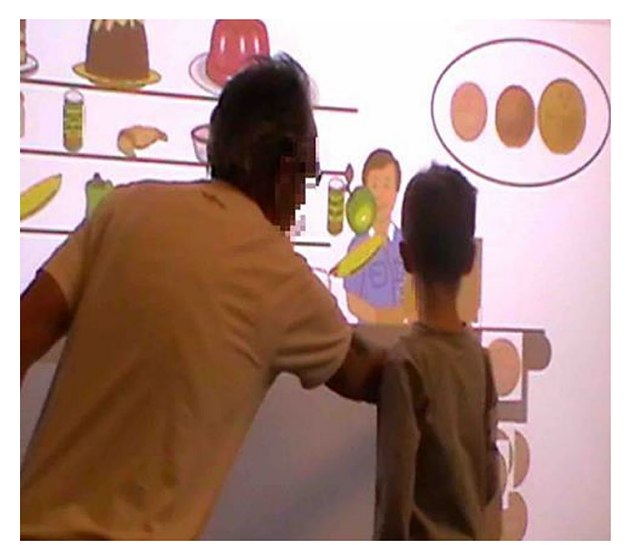

As reflected in the excerpt above, the teacher instructs children using short direct communication, utilizing both verbal and non-verbal modes. For instance, the preschool teacher points and gives comments about how Emil should conduct the activity. The instruction is direct when the teacher suggests, "You can put the coins (money) here next to the cashier so we can see them".

\section{Recruitment}

This scaffolding function covers actions such as inviting children to the task, providing space for reflection, providing feedback, and affirming children's reflections.

Inviting children to accomplish activities is one of the teachers' actions in the scaffolding process. In the conducted observations, the preschool teachers invite children to come to the board and solve a given problem. By inviting a child, and in some cases two or three children, the teacher can scaffold their participation in the activities designed.

Providing space for children's reflections in activities is another way of acting which is commonly seen in the conducted observations. In the example below, the teacher seems to create a space to scaffold the child, Elin, through giving her time to formulate and restructure her thoughts.

\section{Excerpt from Teaching Activity E: 2: Classification of Objects Based on Their Size}

Teacher: ((Looks at Elin)) In which order do you want to put the pigs? Which one of them do you want to start with?

Elin: ((Looks at the board and is completely silent)) (8 s) ((Starts with the little pig))

Teacher: ((Looks at the board)) You will start with the smallest one; yes, which one do you think will be next?
((Sits next to the board and looks at what Elin does on the IWB))

Elin: ((First puts the little pig on the line, then she moves the little pig up the board and then she moves the largest pig and puts it on the line. Then she puts the middle pig on the line followed by the smallest one))

Teacher: Yes, now you can sit down and tell us what you were thinking.

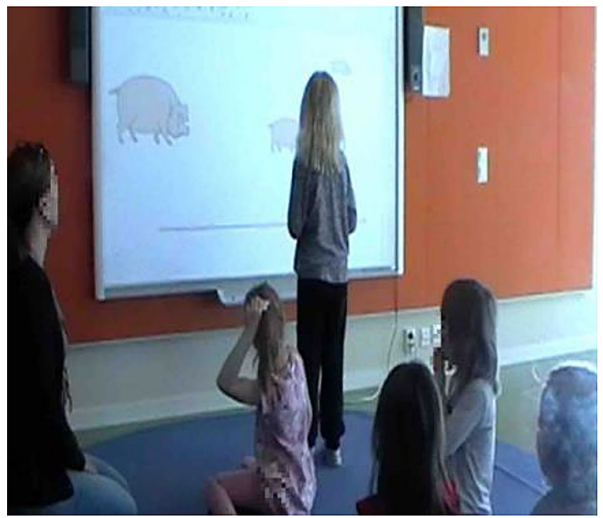

As shown, Elin is quiet at first and does not move for $8 \mathrm{~s}$. Then she moves the little pig. The teacher looks at Elin and waits for her reflection. In these situations, the teacher does not react immediately but is waiting for the child, Elin, to fulfil the task.

In situations when the teacher is using IWB, providing feedback has a critical role to keep the children within the activity. In the observed teaching situations, teachers carefully listen and pay attention to the children, responding to their diverse experiences. Providing verbal feedback like "you will start with the smallest one" and "yes, which one do you think will be next?" (see excerpt above) as well as emotional feedback such as listening, nodding and smiling, children can be encouraged to take further steps within the activity.

In some observed actions, the teachers seem to affirm children's reflections. Affirmation and approving children's reflection are often seen as critical in a scaffolding process. For instance, in the following excerpt, the child, Fredrik, reflects on that a circle is round.

\section{Excerpt from Teaching Activity A: 2: Location of Geometrical Shapes}

Teacher: What does a circle look like?

Fredrik: ((looks at the teacher)) [after (.) It's round

Teacher: Yes, exactly, it's round. Take a circle and put it above the purple rectangle 


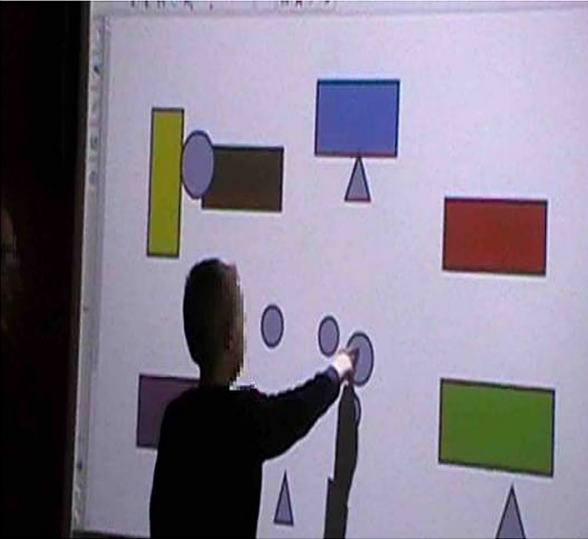

In the next line, the preschool teacher affirms Fredrik's reflection indicating that his approach is correct by saying, "Yes, exactly, it's round.".

\section{Mutual Enjoyment}

Mutual enjoyment addresses the ways that the teacher is emotionally involved by being responsive and sensitive. This scaffolding function can be addressed when the preschool teachers are watching and laughing together.

The participating teachers use watching as an action of scaffolding in their teaching. Watching the children's actions and reflections may signify that teachers actively listen to and focus on what children say and do as well as how they act when they are working with the IWB.

Teachers, further, apply laughing together as another action in the scaffolding process. Laughing can signify teachers' interest in the ways children think or act regarding given mathematical concepts. The following excerpt demonstrates the ways teachers act to support children emotionally.

\section{Excerpt from Teaching Activity B: 2: Classification of Geometrical Forms}

Teacher: Can anyone drag and drop one of the forms given and say what it is? ((points to the geometrical forms on the IWB))

Tommy: ((approaches the board. He drags a circle and drops it over an 8-sided form)) It is called a circle.

Teacher: ((smiles and looks towards Tommy)) Oh, is it the right place for it? Should we put a circle there?

Tommy: ((laughs)) (.) No. I am just kidding.

Teacher: ((smiles)) Do you want to tease us? ((looks at Anton)) [After (.) Anton do you know where Tommy should place the circle?

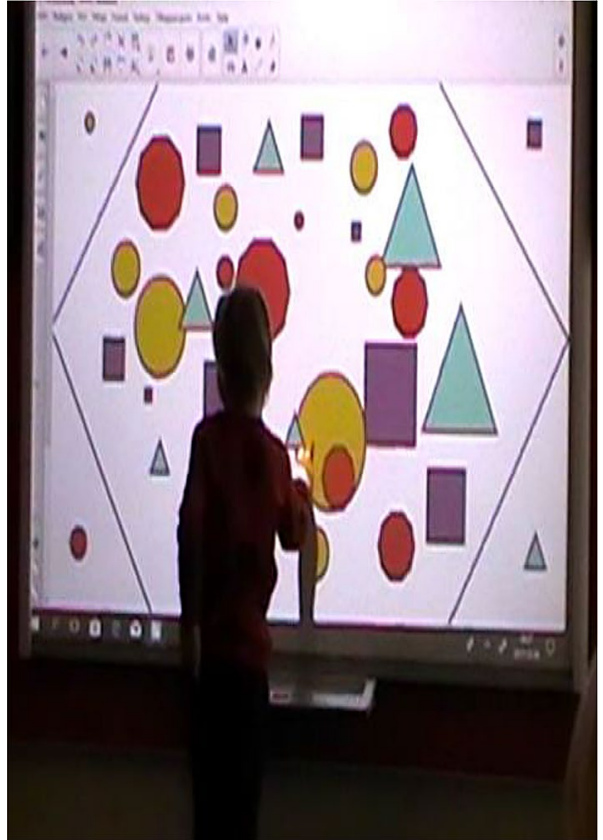

In the activity above, children were asked to classify the given forms on the IWB. The teacher B gives the children freedom to explore the given forms in their own ways. For instance, Tommy drags a circle on the IWB indicating loudly the name of the shape he chooses, "circle". He drags and drops the circle under the eight-sided shape. The teacher seems confused, smiling at the child's response. The teacher, with a kind expression, wonders if the circle can be matched with the eight-sided shape.

\section{Frustration Control}

This scaffolding function addresses the ways teachers approach physically, i.e. standing or sitting beside the children.

By approaching the child when the child conducts an activity on IWB, the teacher seems to try to minimize children's stress. The teachers' physical presence might create an atmosphere where the children will not feel alone or helpless when fulfilling an activity or solving a problem on the IWB.

In several observed instances, children are not able to drag or paint the given object. When the teacher approaches the child, or stands/sits next to the child, the child often solves the problem immediately. Such physical presence might help children to control frustration and focus on the task. 


\section{Reduction in Degrees of Freedom}

This scaffolding function addresses preschool teachers' actions to scaffold children through simplifying the task, filling in the blanks and confirming.

Simplifying and reducing components of an activity by marking one object at a time can provide opportunities for children to focus only on the marked object and then relate the object to other presented objects on the IWB. Further, highlighting and marking one object or aspect of a phenomena at a time can increase children's attention to the given activities. The following excerpt about exploring positions of the objects in relation to other objects exemplifies how simplifying can scaffold children's learning. There are four different objects on the IWB where one of them can be moved at a time.

\section{Excerpt from Teaching Activity B:2: Position of the Objects}

Teacher: ((sitting next to the board)). Where has Lotta placed the bus? You can raise your hands and answer the question, where did she put the bus on the board?

Moa: ((looks at the board)) (.) Next to the three.

Teacher: Is there anything else you can add? ((points towards the bottom of the board)) [after (.) What is at the bottom? (.)

Linda: It is between two and three.

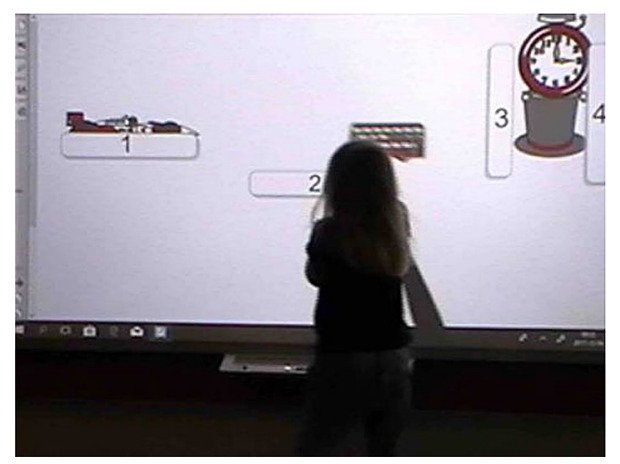

As indicated in the excerpt above, the teacher simplifies the given activity by asking, "Where has Lotta placed the bus?". The teacher marks where the bus is on the IWB, and by doing so, reduces the components of the activity. The child, Moa, answers the teacher's question by saying that the bus is next to the three.

Filling in the blanks addresses the ways that preschool teachers provide and fill in some information during the given activity. The following excerpt exemplifies ways that the teacher fills in the blanks to classify the geometrical shapes according to their features.

\section{Excerpt from Teaching Activity D: 1: Classification of Geometrical Forms}

Teacher: ((points to the shape on the IWB)) Octagon looks like a circle too.

Julia: ((looks at the teacher)) I don't think so.

Edward: Neither do I.

Teacher: [Don't you believe so? ((looks at the children and smiles)) [after (.) What makes it different from a circle?

Julia: I don't know.

Max: They have sides.

Teacher: Yes, they have sides, eight sides.

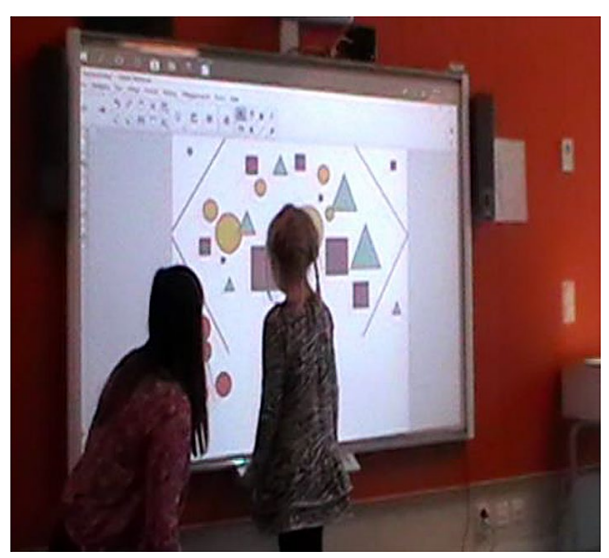

The preschool teacher informs children by saying, "Octagon looks like a circle too". Giving such information while pointing at the octagon on the IWB, the preschool teacher introduces the geometrical shape of an octagon, which is different from, but similar to a circle. Through this action, the teacher opens up for discussions concerning features of geometrical shapes.

Confirming the children's responses to fulfil the task is another action which preschool teachers apply to reduce degrees of freedom. By doing so, the preschool teacher confirms the child's actions as if he/she is accomplishing the given task precisely, even when they are not fulfilling the task correctly. Having such a strategy may lead children to feel and have an understanding that they can manage the task.

In the following excerpt, the teacher and the children are working with an activity about the classification of animals on the IWB. They discuss animals' differences and 
similarities. The teacher teaches children to classify animals by their characteristics such as how many legs they have.

\section{Excerpt from Teaching Activity B: 3: Classification of Animals}

Teacher: ((looks at Emma)) How many legs does the fish have?

Emma: Two

Teacher: Has it? ((points to the fish on the IWB looks at Emma))[after (.) They may have legs inside; in their body.

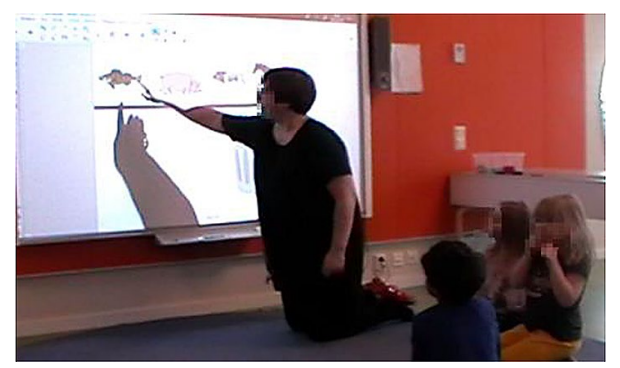

As shown, when the child, Emma, replies that the fish has two legs, the teacher reformulates her answer without highlighting that Emma's answer is incorrect. Instead, the teacher says: "The fish may have legs inside their body". The teacher, through confirming and rephrasing the child's answer, seems to try to promote Emma's self-esteem and to keep the child focused on the task.

\section{Participation in the Activity}

Participating and doing the same activities with the children on the IWB is another way of action that is indicated in a number of the observed teaching situations. In these situations, teachers not only support children by approaching and standing beside children in the activity, but they participate actively as contributors. For instance, in the following excerpt the teacher and the children work with an activity about measurement. The children are first asked to find and measure something in the classroom with building blocks. Further, they are going to show the amount of building blocks on the IWB by dragging squares. The teacher also takes a brush and measures with building blocks, and performs the activity together with the children.

\section{Excerpt from Teaching Activity D: 3: Measurement}

Teacher: ((looks at the building blocks)) [after (.) can you help me count?

Teacher and children: ((point to the building blocks, which are beside the brush)) one, two, three, four, five, six and seven

Teacher: ((looks at the board and begins to drag the square to stack on the IWB)) Do you think they can be placed here on the IWB? ((drags the square)) one, two, three, four, five, six and seven

Martina: ((points to the teacher)) you have the longest Teacher: ((looks at the other children's stacks on the board))(.) Do I have the longest? ((smiles)
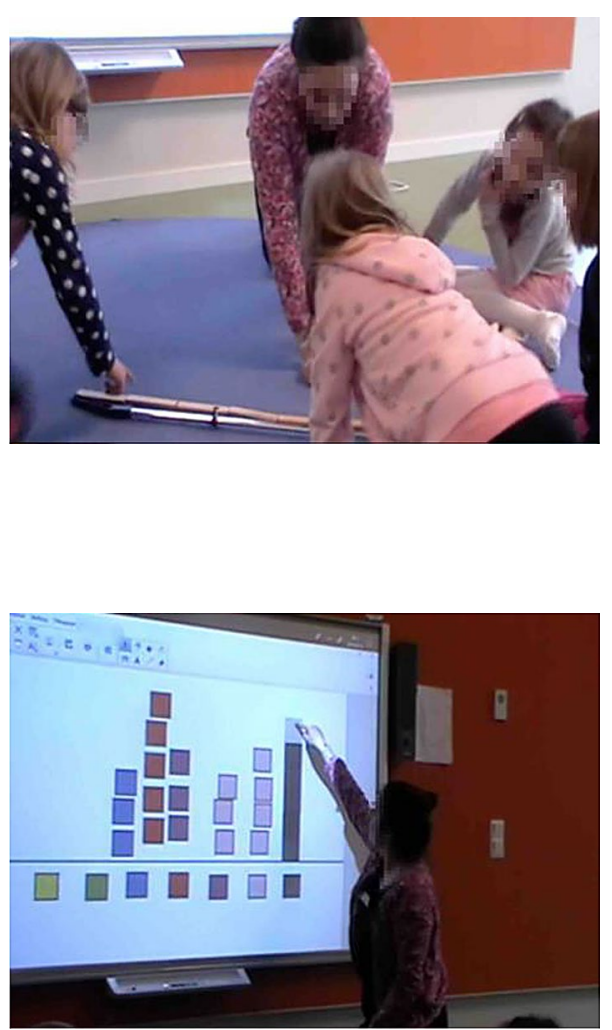

This example shows how the teacher takes an active role in the activity she is present in both body and soul. It may indicate that it is not enough for teachers to sit next to the child when the child conducts an activity. 


\section{Marking Critical Features}

This scaffolding function can be highlighted when the preschool teachers challenge children's perception in the task and explain facts. Challenging children's perception can be reflected in a variety of ways. The following excerpt highlights an instance of actions where teachers challenge children to work with an activity about classifying animals on IWB.

\section{Excerpt from Teaching Activity B: 3: Classification of Animals}

Teacher: Which one of the animals should be removed? Irma: ((looks at the teacher)) (.) The horse.

Teacher: ((drags the horse's picture and puts it above the trash box $))($.)...Is there something special about the horse so that we should remove it before the other animals? ((points to other animals on the IWB)) Maybe they have more legs, or? How many legs do they have?

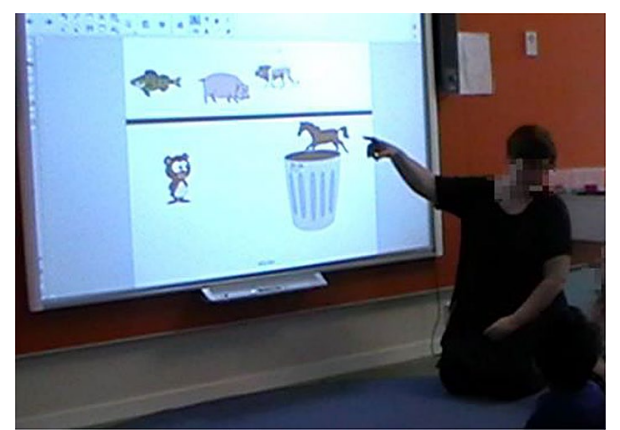

The teacher emphasizes important features in classifying objects i.e. on differences and similarities. In order to help children to realize the differences and similarities between the horse and other animals, the teacher challenges children's perception by posing questions, such as "Is there something special about the horse so that we should remove it before the other animals?" The teacher further drags and drops images of the animals and makes contrasts between the animals on the IWB.

In a number of the observed teaching situations, the preschool teachers explain facts to clarify the possible causes and consequences of the addressed facts (see excerpt E:1).

\section{Excerpt from Teaching Activity E: 1: Measurement}

Linnea: ((drags the fourth square on the IWB))

Teacher: Four.
Linnea: ((drags the fifth square and puts it over the other squares))

Teacher: ((points to the squares on the IWB)) [After (.) Five, you were five squares tall.

Amelia: ((comes to the board and shows with her hand)) Oh, how short Linnea is.

Teacher: ((looks at Amelia)) No not in reality, but we need five squares to show how tall Linnea is.

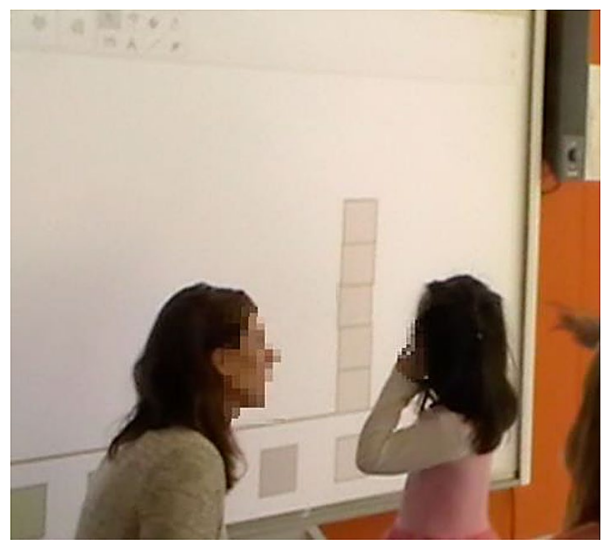

In this activity on the IWB, squares as means of measurement are used to show how tall Linnea is. Amelia, however, measures with her hand the presumed height of Linnea. The teacher explains a set of facts by saying, "No not in reality, but we need five squares to show how tall Linnea is".

\section{Demonstration}

Demonstrating addresses teachers' actions including displaying a solution, explaining solutions and referring back to the pervious activity.

As indicated in the following excerpt, the teacher models by displaying solutions when she observes that Vincent has tried several times and failed to follow a more complex type of instruction. By showing her hand movement slowly in a way that Vincent can see the screen properly, the teacher demonstrates how he can rotate the piece on the IWB to complete the given puzzle.

Verbally explaining solutions is another action that the teachers use in the scaffolding process. For instance, in the excerpt below, the teacher not only displays the solution process but also explains by verbally addressing how children can fulfil the given task, saying, "Adjust two other pieces inwards, then they can have a whole circle". 
As exemplified in the following excerpt, the teacher referring back to the pervious activity helps children to fulfil the activity on the board.

\section{Excerpt from Teaching Activity A: 5 and C: 2: Part and Whole II}

Teacher A: Vincent, can you come to the board and try the puzzle?

Teacher C: ((is looking at the other children who are sitting in front of the IWB))

Teacher C: Is it a circle also? ((She/he compares this puzzle with the pervious puzzle which the children did))

Adam: ((looks at the teacher C)) Yes, a very small circle. Vincent: ((tries to put the puzzle pieces together and makes a circle. Vincent seems unable to complete the puzzle))

Teacher A: ((comes to the board and stays near the child)) (.) Wait Vincent look at me. Turn this one around [((Teacher demonstrates how Vincent can put the pieces together)) Well done Vincent ((Teacher rotates the pieces illustrating how Vincent can do this)) do you think it can fit then? ((Teacher rotates the last piece of the puzzle)) Vincent: (.) ((looks at the IWB and nods. He quickly begins to rotate the piece. Vincent stays still))

Teacher A: ((comes back in front of the board and stands next to Vincent. He slowly demonstrates how Vincent can rotate the pieces)) Vincent: ((seems to try to rotate and place the pieces in their place))

Teacher: (.) Adjust two other pieces inwards, then they can make a whole circle.

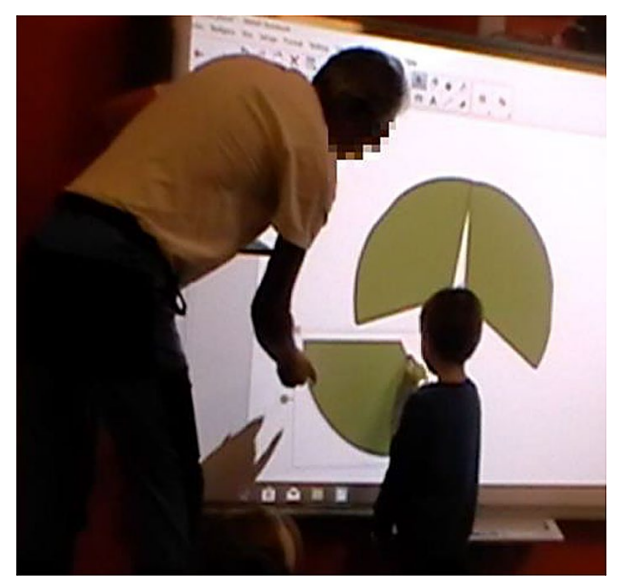

As a final remark, it can be noted that Adam's answer "very small circle" indicates that he elaborates with the idea that apart from the size of every piece, fewer pieces of a puzzle can form a little circle.

\section{Discussion}

The current study aimed to explore preschool teachers' actions in a context where IWB is used. The findings of the study reveal that preschool teachers use different actions in relation to different scaffolding functions. By characterizing teachers' actions within different functions, the relationship between action and function of scaffolding were clarified. Six of these functions, including recruitment, direction maintenance, marking critical features, reduction in degrees of freedom, frustration control and demonstration were aligned with Wood et al.'s (1976) theoretical framework. More importantly, by identifying two additional functions, (i.e., mutual enjoyment and participation in the activity), the study contributed to the development of Wood et al.'s (1976) theoretical framework. The study, further, brought in rich details of the teachers' actions in relation to the scaffolding functions. Our analysis expanded and deepened the understanding of the scaffolding process. These findings, thus, can be used as a frame for the visualization of teachers' different actions of scaffolding where digital technologies are employed. Introducing teachers' actions of scaffolding in relation to functions of scaffolding can inform preschool teachers' professional development, as underlined in the Swedish Curriculum.

Preschool teachers' active participation and enjoyment are not only important steps in fulfilling the activities, but can also scaffold children's learning at a higher level (cf. Stephen 2010). This is particularly exemplified in the observations when preschool teachers participate in the activities on IWB and take an active role, to teach valuable features of measurement, classification, value of money as well as numbers and order. The findings are aligned with the results of previous studies (cf. Plowman and Stephen 2007, 2013) in terms of indirect (distal) and direct (proximal) forms of guided interactions (i.e., teachers' presence and active support of children's interactions can promote children's learning).

Challenging, Approaching, and Providing feedback were the most referred actions of scaffolding that teachers used in their teaching when IWB was used. The greater use of these actions may signify the importance of such actions in the scaffolding process. Thus, it would be interesting to explore if and how the use of these actions in the scaffolding process (i.e., Challenging, Approaching, and Providing feedback) can help teachers in their use of IWB.

It should be noted that this study did not provide answers concerning how the addressed teachers' actions contribute to children's learning. Other studies can further examine how teachers' actions when using IWB can contribute particularly to children's learning and development. 
It should also be noted that this sample is from one single preschool and it is likely that additional actions can be identified when a larger sample of preschool teachers are followed in their daily work with IWB.

Teaching in preschool is a complex task which is constantly influenced by pedagogical and technical developments. According to the findings presented, we do not mean that preschool teachers' actions of scaffolding can occur only in preplanned teaching activities using digital technologies, but we do argue that the ways preschool teachers scaffold children in the learning process can inform how digital technologies can be used in preschool educational practices. These findings are important as a contribution to current knowledge about teachers' actions in the process of supporting young children's learning and development. The findings are also important since the results in this study contribute to our understanding of preschool teachers' actions and competences when faced with changes towards more pedagogical and school-preparing activities in preschool (cf. Sheridan et al. 2011). In a broader sense, this study also gives a contribution to the field of early childhood education since early interventions, such as teachers' actions, are particularly essential for the child's early years and later on in life (Ruhm and Waldfogel 2012; The Swedish Research Council 2015).

Acknowledgements Open access funding provided by Örebro University.

Open Access This article is distributed under the terms of the Creative Commons Attribution 4.0 International License (http://creativeco mmons.org/licenses/by/4.0/), which permits unrestricted use, distribution, and reproduction in any medium, provided you give appropriate credit to the original author(s) and the source, provide a link to the Creative Commons license, and indicate if changes were made.

\section{References}

Björklund, C. (2012). What counts when working with mathematics in a toddler-group? Early Years, 32(2), 215-228.

Bourbour, M., Vigmo, S., \& Pramling Samuelsson, I. (2014). Integration of interactive whiteboard in Swedish preschool practices. Early Child Development and Care, 185(1), 100-120.

Bruner, J. S. (1978). The role of dialogue in language acquisition. In A. Sinclair, R. Jarvella, \& W. J. M. Levelt (Eds.), The child's conception of language. New York: Springer-Verlag.

Bruner, J. (1983). Child's talk. New York: Norton.

Copple, C., \& Bredekamp, S. (2009). To be an excellent teacher. In C. C. S. Bredekamp (Ed.), Developmentally appropriate practice in early childhood programs serving children from birth through age 8 (pp. 33-52). Washington, DC: NAEYC.

De Vita, M., Verschaffel, L., \& Elen, J. (2014). Investigating the distinctive role of the interactive whiteboards for mathematics teaching. The Eurasia Proceedings of Educational \& Social Sciences (EPESS), 1, 141-152.

De Vita, M., Verschaffel, L., \& Elen, J. (2018). The power of interactive whiteboards for secondary mathematics teaching: two case studies. Journal of Educational Technology Systems, 47(1), 50-78.
Edman Stålbrandt, E., \& Hössjer, A. (2007). Scaffolding and interventions between students and teachers in a learning design sequence teachers' scaffolding and interventions. Revista Semestral da Associação Brasileira de Psicologia Escolar e Educacional (ABRAPEE), 11, 37-48.

Jönsson, I., Sandell, A., \& Tallberg-Broman, I. (2012). Change or paradigm shift in the Swedish preschool? : Sociologia, Problemas E Praticas.

Lindqvist, G., \& Vinterek, M. (2015). Att utmana och stimulera barns utveckling och lärande i förskolan-En observationsstudie i fem förskolor. Stockholm: Skolverket.

Masoumi, D. (2015). Preschool teachers use of ICTs: Towards a typology of practice. Contemporary Issues in Early Childhood (CIEC), $16(1), 5-17$.

McGarr, O. (2009). The development of ICT across the curriculum in Irish schools: A historical perspective. British Journal of Educational Technology, 40(6), 1094-1108.

Mercer, N., Hennessy, S., \& Warwick, P. (2010). Using interactive whiteboards to orchestrate classroom dialogue. Technology, Pedagogy and Education, 19(2), 195-209.

Mercer, N., \& Littleton, K. (2007). Dialogue and the development of children's thinking: A sociocultural approach. London: Routledge.

Nikolopoulou, K. (2014). Educational Software Use in Kindergarten. In P. P. C. Karagiannidis \& I. Karasavvidis (Eds.), In Research on e-learning and ICT in education: Technological, pedagogical and instructional perspectives. New York: Springer.

Plowman, L., \& Stephen, C. (2003). A "Benign Addition"? research on ICT and pre-school children. Assisted Learning, 19, 149-164.

Plowman, L., \& Stephen, C. (2005). Children, play, and computers in pre-school education. British Journal of Educational Technology, $36(2), 145-157$.

Plowman, L., \& Stephen, C. (2007). Guided interaction in pre-school settings. Computer Assisted Learning, 23, 14-26.

Plowman, L., \& Stephen, C. (2013). Guided interaction: exploring how adults can support children's learning with technology in preschool settings. Hong Kong Journal of Early Childhood, 12(1), $15-22$.

Pramling Samuelsson, I., \& Asplund Carlsson, M. (2008). The playing learning child: Towards a pedagogy of early childhood. Scandinavian Journal of Educational Research, 52(6), 623-641.

Ruhm, C. J., \& Waldfogel, J. (2012). Long-term effects of early childhood care and education: Nordic economic policy review. Economics of Education, 23-51.

Sheridan, S., Williams, P., Sandberg, A., \& Vuorinen, T. (2011). Preschool teaching in Sweden-A profession in change. Educational Research, 53(4), 415-437.

Siraj-Blatchford, I. (1999). Early childhood pedagogy: Practice, principles and research. In P. Mortimer (Ed.), Understanding pedagogy and its impact on learning (pp. 20-45). London: Paul Chapman.

Siraj-Blatchford, I. (2009). Conceptualising progression in the pedagogy of play and sustained shared thinking in early childhood education: A Vygotskian perspective. Education and Child Psychology, 26(2), 77-89.

Stephen, C. (2010). Pedagogy: The silent partner in early years learning. Early Years, 30(1), 15-28.

The Swedish National Agency for Education. (2015). Curriculum for the preschool Lpfö 98: Revised 2010 and 2015. Stockholm: Skolverket.

The Swedish National Agency for Education. (2018a). Revised curriculum for the preschool. Stockholm: Skolverket.

The Swedish National Agency for Education. (2018b). Statistik om barn och personal i förskolan. Stockholm: Skolverket.

The Swedish Research Council. (2015). Preschool: Early intervention. Stockholm: Skolverket.

The Swedish Research Council. (2017). Good Research Practice. Stockholm: Skolverket. 
UNICEF. (2008). The child care transition: A league table of early childhood education and care in economically advanced countries (Florence ed.). Florence: UNICEF Innocenti Research Centre.

van de Pol, J., Volman, M., \& Beishuizen, J. (2010). Scaffolding in teacher-student interaction: A decade of research. Educational Psychology Review, 22(3), 271-296.

Vygotsky, L. S. (1978). Mind in society: The development of higher psychological processes. Cambridge: Harvard University.

Warwick, P. \& Mercer, N. (2011). Using the interactive whiteboard to scaffold pupils' learning of science in collaborative group activity. Paper presented at the EARLI 2011, Conference. University of Exeter.
Wells, G. (1999). Dialogic inquiry: Towards a sociocultural practice and theory of education. New York: Cambridge University Press.

Wood, D., Bruner, J., \& Ross, G. (1976). The role of tutoring in problem solving. Child Psychology and Psychiatry, 17, 88-100.

Publisher's Note Springer Nature remains neutral with regard to jurisdictional claims in published maps and institutional affiliations. 